\title{
Elites estatais no Sul do Brasil: prosopografia da alta administraçáo republicana no Rio Grande do Sul, 1889-1937
}

\author{
Flavio Madureira Heinz $z^{*}$ \\ ${ }^{1}$ Universidade Federal Rural do Rio de Janeiro, Seropédica/RJ - Brasil
}

Marcelo Vianna ${ }^{2^{* *}}$

${ }^{2}$ Instituto Federal de Educação, Ciência e Tecnologia do Rio Grande do Sul, Osório/RS - Brasil

\section{RESUMO}

O texto traz os resultados de um estudo prosopográfico de 130 membros da alta administraçáo pública e da elite política do Estado do Rio Grande do Sul, atuantes durante a Primeira República, e estendendo-se do início do período, em 1889, até 1937, data que marca o fim do primeiro governo Vargas, com o golpe do Estado Novo e o fechamento do sistema político representativo no país. O estudo lançou luz sobre o perfil social e profissional de altos dirigentes políticos do Estado, entáo atuantes em nível regional ou nacional. Pela metodologia e critérios de análise utilizados, o trabalho busca também a realização de comparaçóes com estudos anteriores sobre elites políticas de outros estados brasileiros, ampliando o conhecimento acerca da atuação dos grupos políticos regionais do Brasil da Primeira República às vésperas do Estado Novo. Ao fazê-lo, a pesquisa relativiza a perspectiva excepcionalista que dominou por muito tempo a historiografia política sobre o Rio Grande do Sul - notadamente a ideia de uma administração científica não-oligárquica fundada no Positivismo -, embora reafirme alguns aspectos historicamente associados ao republicanismo do Sul do país, como a baixa renovação de quadros políticos e, por conseguinte, a longevidade das carreiras públicas na alta administração pública.

Palavras-chave: elites regionais; prosopografia; base de dados; política regional; história comparada.

DOI: http://dx.doi.org/10.1590/2237-101X02204607

Artigo recebido em 10 de agosto de 2019 e aceito para publicação em 29 de abril de 2020.

* Professor da Universidade Federal Rural do Rio de Janeiro / Instituto de Ciências Humanas e Sociais / Departamento de História e Relaçôes Internacionais, Seropédica/RJ - Brasil. E-mail: fmheinz@gmail.com. ORCID: https://orcid.org/0000-0002-2906-7458.

** Pesquisador do Instituto Federal de Educação, de Ciência e Tecnologia do Rio Grande do Sul / Campus Osório, Osório/RS - Brasil. E-mail: maverian1@gmail.com. ORCID: https://orcid.org/0000-0002-3687-3474.

A pesquisa que deu origem a este artigo foi financiada pela Capes - Chamada no 7/2011 - e Fundação de Amparo à Pesquisa do Estado do Rio Grande do Sul. 


\title{
State elites in Southern Brazil: prosopography of high-ranking republican officials in Rio Grande do Sul, 1889-1937
}

\begin{abstract}
This article presents the results of a prosopographical study of 130 high-ranking officials and members of the political elite of Rio Grande do Sul, from 1889, the beginning of the so-called First Republic, to 1937, when the Estado Novo coup d'État and Congressional shutdown marked the end of the first Vargas government. The study sheds light on the social and professional profile of senior state politicians, then active at the regional or national level. Through its methodology and analysis criteria, the study also seeks to compare previous studies on political elites in other Brazilian states, increasing the knowledge about the performance of Brazil's regional political groups throughout the First Republic and Vargas government. In doing so, the research relativizes the exceptionalist perspective that dominated the political historiography of Rio Grande do Sul for a long time, especially the prevalence of a non-oligarchical scientific administration based on Positivism. This study also reaffirms some aspects historically associated with republicanism in Southern Brazil, such as the low renewal of political cadres and, thus a longevity of careers in public administration.
\end{abstract}

Keywords: regional elites; prosopography; databases; regional politics; comparative history.

\section{Élites estatales en el sur del Brasil: prosopografía de la alta administración republicana en Rio Grande do Sul, 1889-1937}

\section{RESUMEN}

El texto presenta los resultados de un estudio prosopográfico de 130 miembros de la administración pública y política del Estado de Rio Grande do Sul, actuando desde 1889 hasta 1937. El estudio resalta el perfil de los altos dirigentes que luego actuaban a nivel regional o nacional. A través de la metodología utilizada, el trabajo busca hacer comparaciones con estudios previos sobre elites políticas de otros estados brasileños. Al hacerlo, la investigación relativiza la perspectiva que he dominado la historiografía política de Rio Grande do Sul, basada en la idea de una administración científica no oligárquica fundada en el positivismo. Palabras clave: elites regionales; prosopografía; base de datos; política regional; historia comparativa. 
No final dos anos 1960, três pesquisadores norte-americanos, Joseph Love, Robert Levine e John Wirth planejaram e iniciaram a execução de uma pesquisa sobre as elites regionais no Brasil da Primeira República, execução que se prolongou até quase fins da década seguinte. Dessa pesquisa resultaram os livros de Wirth (1977) sobre Minas Gerais, de Love (1980) sobre São Paulo, e de Levine (1978) sobre Pernambuco. ${ }^{1}$ Os títulos das três obras eram formados de maneira idêntica, levando o nome do estado seguido pela expressão "in the Brazilian Federation, 1889-1937”. Na versão brasileira, publicada pouco tempo depois do lançamento nos EUA, o título era precedido de uma palavra que recuperava características gerais, talvez se pudesse dizer "clichês", associada a cada estado na história do país. Assim, A Locomotiva (destacando a pujança econômica do estado), para Sáo Paulo, O Fiel da Balança (lembrando o papel fundamental dos políticos mineiros no equilíbrio de poder na Primeira República), para Minas Gerais, e a velha Usina (evocando o passado açucareiro e do peso político dos senhores de engenho), para Pernambuco. No total, 753 membros de elites desses três estados, sendo 263 paulistas, 214 mineiros e 276 pernambucanos, compunham o grupo analisado.

A pesquisa, que levou dois anos para ser planejada, levou os pesquisadores ao Brasil por pelo menos um ano, entre 1969 e 1970, e a muitos retornos nos anos subsequentes (HEINZ, 2003). Foi o primeiro esforço bem-sucedido de uma pesquisa coordenada, envolvendo vários pesquisadores e com um desenho metodológico original, sobre elites regionais da Primeira República. Esse esforço, em que se exploraram temas como a economia regional, as "relaçôes fiscais entre estados e governo federal, o problema da integração dos estados na nação, as mentalidades e o problema de como se manifesta a lealdade em relação à nação", contou com o aporte decisivo da inovação tecnológica da época: "houve [...] a possibilidade, na década de 1960, de informatizar todos os dados, de utilizar o computador para organizar e analisar as tendências estatísticas" (HEINZ, 2003, p. 170). Love já havia realizado sua tese, defendida na Universidade de Columbia, em 1967, sobre o regionalismo gaúcho (LOVE, 1975)2², trabalho que contribuiria para a formataçáo da pesquisa coordenada de $1969^{3}$. Contudo, o estudo da história política e social das elites regionais, e, especialmente, a análise prosopográfica da elite regional, desenvolvida na pesquisa coordenada, nunca seria retomada para o caso do Rio Grande do Sul. ${ }^{4}$

\footnotetext{
${ }^{1}$ Um quarto estudo, de Ralph della Cava, sobre o Rio de Janeiro, também estava previsto, mas foi abandonado.

${ }^{2}$ Originalmente publicada pela Stanford University Press em 1971 sob o título Rio Grande do Sul and Brazilian regionalism, 1882-1930.

3 "Em parte baseamos o estudo no que eu já havia feito para o Rio Grande do Sul, onde eu tinha começado a entrar na questáo das elites. Eu tinha estudado as origens regionais dos titulares dos ministérios na Primeira República para entender a importância do Rio Grande do Sul. Aquele foi um período em que, na ciência política e na História, havia muito interesse pelas elites" (HEINZ, 2003, p. 170).

4 "É uma pena que não tenhamos tido a oportunidade de voltar ao Rio Grande do Sul para fazer esses mesmos tipos de estudos das elites, mas o tempo foi limitado e levamos dez anos para escrever os livros" (HEINZ, 2003, p. 170).
} 
Os trabalhos de Love, Wirth e Levine apresentam um mesmo desenho metodológico e estrutura de capítulos. Cada obra traz sete capítulos intitulados $\mathrm{O}$ homem e a terra; A economia; Sociedade e cultura; Política estadual: homens, eventos, estruturas; A elite política; Estado e país: dimensôes políticas; e Rumo à integração. O capítulo 5, relativo à Elite política, é aquele em que os autores realizam o estudo prosopográfico de cada uma das elites regionais. Ainda, em apêndice, e textos, entre eles uma preciosa Nota sobre as elites, com a definição metodológica detalhada do corpus de análise das populaçóes estudadas - escolhidas por critério posicional -, de ocupantes de altos cargos na administraçáo pública e na política em nível regional (17 a 18 cargos tipificados) e em nível federal (17). O apêndice também inclui todas as categorias e variáveis utilizadas (aproximadamente cem) e os resultados estatísticos alcançados. Sob todos os aspectos são trabalhos alentados, que trazem uma reflexão metodológica densa e uma execução técnica precisa.

Em 1991 Joseph Love e Bart Barickman revisitaram as pesquisas originais em um artigo intitulado "Regional elites" (LOVE, 2006)5, em que realizaram "comparaçôes sistemáticas entre as três elites regionais [...] analisando uma nova elite resultante; adicionando e analisando novos dados; colocando - com novas técnicas estatísticas -, novas questôes a velhos dados; e comparando a elite ampliada resultante com outras elites políticas" (LOVE; BARICKMAN, 2006, p. 77), novo tratamento dos dados coletados à época da execução da pesquisa, fizeram novas comparaçôes interregionais e criaram um conjunto novo, composto pelos dados das três populaçôes somadas, uma elite ampliada que, com a devida cautela metodológica, poderia servir de retrato provisório de uma elite nacional na Primeira República e durante o primeiro governo Vargas. Parte da decisão de retomar e de se retrabalhar os dados das três grandes pesquisas sobre elites, iniciadas em 1969, já havia sido esboçada num artigo precedente de Love e Barickman, publicado em 1986 pela Hispanic American Historical Review, intitulado "Rulers and Owners - a Brazilian case study in comparative perspective", em que os autores retomam o estudo das elites paulistas (LOVE; BARICKMAN, 1986).

Com o quadro geral de indagaçôes proporcionado por essas pesquisas prosopográficas, e com o suporte metodológico que oferecem a qualquer pesquisador, colocava-se naturalmente a questão de se ampliar o campo de análise pela agregação de novos estudos fundados nos mesmos critérios. A inclusão do caso do Rio Grande do Sul, cuja importância já fora antecipada pelo próprio Love, aparece aqui como um passo natural. Com efeito, projetos comparativos dessa dimensão, que associem procedimentos metodológicos unificados, não sáo comuns na pesquisa histórica, em geral, e na prosopográfica em particular. A escolha da elite administrativa do Rio Grande do Sul da Primeira República e do primeiro governo Vargas serviria, também, a testar uma ideia corrente na historiografia regional, a de que o comportamento político da elite gaúcha dissentia do padrão nacional, oligárquico-liberal,

\footnotetext{
${ }^{5}$ Originalmente publicado em Love (1991, p. 3-22). Este texto foi publicado no Brasil como "Elites regionais" em Heinz (2006a).
} 
pela influência original do pensamento positivista em sua elite política (e não apenas entre grupos republicanos tradicionalmente mais mobilizados, como os militares).

A tese, esposada por Bosi, Trindade e outros, é de que o Rio Grande do Sul, afastado do liberalismo das elites brasileiras recém-convertidas ao republicanismo, e conduzido por uma elite republicana não-pactuada com os velhos liberais monarquistas (por ela impedidos de fazer uma reconversão pragmática ao republicanismo, como fora a regra em quase todo o país), elite de corte autoritário, modernizador e positivista, produzira, na Primeira República, um esboço de "administração científica" sem equivalente no país (BOSI, 1992; TRINDADE, 2007; TARGA, 2002; HERRLEIN JR., 2000). ${ }^{6}$

Não obstante, não se trata de replicar pura e simplesmente o modelo já consagrado, o que, por razôes de ordem prática, não parecia exequível, mas de testá-lo, através do acionamento de algumas variáveis cujo levantamento nos parecia possível. Não se trata, pois, de um estudo equivalente aos anteriores, uma vez que trataremos de um número menor de variáveis, mas de uma tentativa de, abrigados sob o mesmo quadro metodológico, oferecer alguns elementos de comparaçáo acerca da natureza da elite regional do Rio Grande do Sul, em relação a suas congêneres de outros estados e à elite ampliada proposta por Love e Barickman.

\section{Metodologia}

O trabalho analisa o perfil da alta administração pública e da elite política do Estado do Rio Grande do Sul utilizando a metodologia da prosopografia (CHARLE, 2006; HEINZ, 2006a; HEINZ; CODATO, 2015). No método prosopográfico, o pesquisador estabelece

um universo a ser estudado e entâo investigar um conjunto de questốes uniformes - a respeito de nascimento e morte, casamento e família, origens sociais e posição econômica herdada, lugar de residência, educação, tamanho e origem da riqueza pessoal, ocupação, religião, experiência em cargos e assim por diante (STONE, 2011, p. 115).

$\mathrm{Na}$ pesquisa, esses dados alimentaram um banco de dados biográficos reunindo 130 indivíduos. Pela metodologia e pelos critérios de análise utilizados, o trabalho possibilita ainda a realização de comparações com estudos anteriores existentes sobre elites políticas de estados brasileiros, ampliando o conhecimento sobre atuaçáo dos grupos políticos regionais do Brasil na Primeira República. Ao utilizar uma metodologia e uma grade de análise consagradas em três estudos sobre a política regional no Brasil republicano, o trabalho

\footnotetext{
${ }^{6}$ Um balanço desse debate historiográfico, envolvendo, portanto, também as posiçóes contrárias a essa corrente, encontra-se em "Elites, estado y reforma en Uruguay y Brasil meridional: castilhismo y batllismo en perspectiva comparada. El caso de las elites de Rio Grande do Sul en la transición del siglo XIX al XX” (HEINZ, 2006b).
} 
ofereceu um panorama das características gerais (comuns a todo o país) e particulares da elite político-administrativa na Primeira República no Rio Grande do Sul (WIRTH, 1982; LOVE, 1982; LEVINE, 1980).7 Com efeito, foi replicado parcialmente o modelo proposto pelos pesquisadores citados na análise da elite regional do Rio Grande do Sul, que identifica 34 posiçôes (18 relacionados a posiçóes em nível estadual, 16 em nível federal) no topo da estrutura político-administrativa dos estados à época, com maior ênfase às posiçôes de topo da hierarquia do Executivo e Judiciário, e retendo, no caso do Legislativo, apenas ocorrências de presidência das casas legislativas e lideranças partidárias. ${ }^{8}$

Criou-se um banco de dados a partir do software FileMaker e decidiu-se por privilegiar a análise de carreiras desenvolvidas até $1937^{\circ}$, de modo a que o resultado pudesse ser comparável às bases de dados das pesquisas citadas acima e às tentativas de totalizaçáo mais recentes, como o trabalho de Love e Barickman.

O primeiro indicador da base, o número de indivíduos analisados (130) é bem inferior àquele encontrado para as elites paulista (263), mineira (214) e pernambucana (276). Ainda que os integrantes dos diretórios partidários não tenham sido incluídos (não foram encontrados, até o momento, nas fontes pesquisadas) na população da pesquisa, o baixo número de indivíduos sugere forte concentração de posiçôes ocupadas pelos membros da elite regional do Rio Grande do Sul. Entre as hipóteses está a baixa renovação da elite do Estado.

Isto pode ser observado a partir do levantamento da base de dados sobre 1.612 ocorrências (posiçôes de elite, demais cargos, eventos históricos e honrarias) envolvendo os 130 agentes. Eles ocuparam 218 posiçóes de elite entre os anos de 1889 e 1937, o que perfaz uma média de 1,67 posiçôes de elite por agente ao longo de sua trajetória. No entanto, a concentração é irregular, conforme a tabela 1 , a seguir.

\footnotetext{
${ }^{7}$ Originalmente publicados como WIRTH, John. Minas Gerais in the Brazilian Federation, 1889-1937. Stanford: Stanford University Press, 1977; LOVE, Joseph. São Paulo in the Brazilian Federation, 1889-1937. Stanford: Stanford University Press, 1980; e LEVINE, Robert. Pernambuco in the Brazilian Federation, 1889-1937. Stanford: Stanford University Press, 1980.

${ }^{8}$ São as seguintes as posiçôes, nível estadual: presidente do Estado/governador do Estado, interventor federal, secretário de Estado (Secretaria da Fazenda), secretário de Estado (Secretaria de Obras Públicas), secretário de Estado (Secretaria de Interior), presidente da Assembleia Legislativa, presidente do Tribunal de Justiça (ou Apelação), prefeito municipal/intendente municipal de Porto Alegre, presidente de partido político, comandante da Brigada Militar, chefia de Polícia, membro da Junta Governativa do Estado, secretário de Educação e Cultura, secretário de Agricultura, Indústria e Comércio, líder da maioria da Assembleia Legislativa, líder da minoria da Assembleia Legislativa, presidente do Banco do estado; em nível federal: presidente da República, ministro do Supremo Tribunal Federal, ministro da Fazenda, ministro do Interior e Justiça, ministro da Agricultura, ministro da Marinha, ministro do Trabalho, ministro da Guerra, ministro das Relaçóes Exteriores, ministro da Indústria e Viação, ministro da Viação e Obras Públicas, presidente da Câmara Federal, presidente do Supremo Tribunal Federal, líder da maioria da Câmara Federal, líder da minoria da Câmara Federal, vice-presidente Senado, presidente do Banco do Brasil.

${ }^{9}$ Vale considerar que o uso de base de dados informatizadas contribuem para que os historiadores concebam uma "forma de narrativa histórica" (GIL, 2015, p. 12), superando a fase do acúmulo e organização de dados obtidos nas fontes históricas (VIANNA, 2018).
} 
Tabela 1 - Postos de elite - atuação nos níveis estadual e federal

\begin{tabular}{|c|c|c|c|c|}
\hline & Apenas estadual & Apenas federal & $\begin{array}{c}\text { Estadual e } \\
\text { federal }\end{array}$ & Total \\
\hline Indivíduos & 88 & 25 & 17 & 130 \\
\hline Postos de elite ocupados & 131 & 41 & 46 & 218 \\
\hline $\begin{array}{c}\text { Média postos de elite } \\
\text { ocupados por indivíduo }\end{array}$ & 1,49 & 1,64 & 2,71 & 1,67 \\
\hline
\end{tabular}

Fonte: Banco de Dados Elites Administrativas do RS (1889-1937) / Laboratório de História Comparada do Cone Sul.

Pela tabela, é possível deduzir que há um grupo de agentes (17) mais bem-sucedidos, capazes de ocupar maior número de postos de elite, tanto em nível estadual quanto federal, ao longo de sua trajetória, enquanto os demais se restringem a uma ou outra dessas esferas. Nesse aspecto, destacam-se Osvaldo Aranha e Getúlio Vargas. No nível estadual, a baixa média de postos ocupados $(1,49)$ sugere baixa rotatividade da elite, como os exemplos abaixo:

Quadro 1 - Exemplos de longa duração em postos de elite - nível estadual (1889-1937)

\begin{tabular}{|c|c|c|c|c|}
\hline Posiçáo & Agentes & Média de tempo & Maior tempo & $\begin{array}{c}\text { Ocupante com maior } \\
\text { tempo }\end{array}$ \\
\hline $\begin{array}{c}\text { Secretário de } \\
\text { Obras Públicas }\end{array}$ & 12 & $1.194,71$ dias & 6.652 dias (18,2 anos) & $\begin{array}{c}\text { João José Pereira Parobé, } \\
\text { engenheiro (1890-1906; } \\
1913-1915)\end{array}$ \\
\hline $\begin{array}{c}\text { Presidente da } \\
\text { Assembleia Le- } \\
\text { gislativa }\end{array}$ & 11 & $1.130,5$ dias & 7.096 dias (19,4 anos) & $\begin{array}{c}\text { Manoel Theóphilo Bar- } \\
\text { reto Vianna, engenheiro } \\
\text { (1908-1928) }\end{array}$ \\
\hline $\begin{array}{c}\text { Presidente do } \\
\text { Tribunal de } \\
\text { Justiça }\end{array}$ & 11 & $1.816,55$ dias & 7.216 dias (19,7 anos) & $\begin{array}{c}\text { James de Oliveira Franco } \\
\text { e Souza, advogado (1894- } \\
1914)\end{array}$ \\
\hline $\begin{array}{c}\text { Secretário de } \\
\text { Interior }\end{array}$ & 11 & $1.296,07$ dias & 7.763 dias (21,2 anos) & $\begin{array}{c}\text { Protásio Alves, médico } \\
\text { (1906-1926; 1926-1928) }\end{array}$ \\
\hline $\begin{array}{c}\text { Pres./Gov. do } \\
\text { Estado (1889- } \\
1930,1935- \\
1937)\end{array}$ & 12 & 993,56 dias & 9.129 dias (25 anos) & $\begin{array}{c}\text { Borges de Medeiros, } \\
\text { advogado (1898-1908; } \\
1913-1928)\end{array}$ \\
\hline
\end{tabular}

Fonte: Banco de Dados Elites Administrativas do RS (1889-1937) / Laboratório de História Comparada do Cone Sul.

A baixa rotatividade é notável em postos considerados de primeira ordem, como a presidência do Estado do Rio Grande do Sul. Durante o período de Borges de Medeiros no cargo máximo do Poder Executivo estadual, entre os anos de 1898 e 1908, e os anos de 1913 e 1928, Sáo Paulo apresentou uma alternância e regularidade na ocupaçáo do mesmo posto, observando-se a posse de 11 presidentes do Estado. Isso pode indicar que, apesar das máquinas partidárias republicanas terem amplo poder na ocupação do Estado, São Paulo necessitava recompor e acomodar os diferentes grupos de elite, enquanto no Rio Grande do Sul o papel da liderança - justificada por práticas autoritárias e centralizadoras associadas ao 
positivismo doutrinário - possivelmente conferisse legitimidade para a ocupação do cargo sem submissão necessária à alternância, e isso somado à capacidade da liderança em articular e mediar os grupos menores nos municípios. ${ }^{10}$

\section{Aspectos gerais}

$\mathrm{Na}$ sequência apresentamos uma série de dados relativa à formação e origem dos membros da elite político-administrativa do Rio Grande do Sul, bem como à relação entre formação e postos ocupados na carreira. Se em parte esses dados confirmam um padrão comum a outras elites regionais do país à época, de outra sugerem alguma originalidade da configuração social da elite rio-grandense. Assim, se a formação nas Faculdades de Direito - caso de metade do nosso grupo -, é um percurso compartilhado por outras elites regionais, a profissão/ocupação dos pais (não fizemos distinção entre as categorias) sugere um particularismo regional, portanto desviante do padrão nacional: a presença de muitos militares na geraçáo anterior, fato até certo ponto surpreendente face ao baixo prestígio das carreiras militares ao longo de boa parte do século XIX. Contudo, é sempre bom proceder aqui com cautela metodológica. Com quase metade de não-respostas para profissão/ocupação dos pais, é pertinente sugerir que os militares, comumente sinalizados nos registros oficiais, podem também estar sobrerrepresentados uma vez que há possível baixa notificação de atividades mais comuns, como fazendeiro/criador de gado.

Tabela 2 - Profissão/Ocupação dos membros da elite $(\mathrm{N}=130)$

\begin{tabular}{|c|c|c|}
\hline Profissáo/Ocupação & Indivíduos & \% \\
\hline Advogado & 64 & 49,2 \\
\hline Militar & 28 & 21,5 \\
\hline Engenheiro & 17 & 13 \\
\hline Médico & 10 & 7,6 \\
\hline Comerciante & 3 & 2,3 \\
\hline Jornalista & 3 & 2,3 \\
\hline Sem informação & 5 & 3,8 \\
\hline
\end{tabular}

Fonte: Banco de Dados Elites Administrativas do RS (1889-1937) / Laboratório de História Comparada do Cone Sul.

${ }^{10}$ Devido às características políticas do Rio Grande do Sul, o sistema eleitoral sul-rio-grandense permitia sucessivas reeleições para o cargo de presidente do Estado, o que contribuía para manter o baixo índice de rotatividade nos principais postos do Executivo. De certo modo, isso parece refletir nos cargos do Legislativo e do Judiciário, tendo em vista que o sistema eleitoral e o recrutamento da magistratura ainda eram mediados pelo Executivo (AXT, 2011). Isto foi distinto de São Paulo (Constituição Estadual de 1891, artigo 28) e Minas Gerais (Constituição Estadual de 1891, artigo 50), pois vedavam a reeleição para a presidência, o que sugere a busca de coesão política por meio de uma circulação no poder pelas elites regionais. 
Tabela 3 - Profissão/ocupação dos pais $(\mathrm{N}=130)^{11}$

\begin{tabular}{|c|c|c|}
\hline Profissão/ocupação do pai & Indivíduos & \% \\
\hline Militar & 23 & 15,65 \\
\hline Fazendeiro/estancieiro & 19 & 12,93 \\
\hline Político & 18 & 12,24 \\
\hline Funcionário público & 8 & 5,44 \\
\hline Professor & 7 & 4,76 \\
\hline Comerciante & 6 & 4,08 \\
\hline Magistrado & 5 & 3,4 \\
\hline Sem informação & 61 & 41,5 \\
\hline
\end{tabular}

Fonte: Banco de Dados Elites Administrativas do RS (1889-1937) / Laboratório de História Comparada do Cone Sul.

Tabela 4 - Formação acadêmica/Instituição $(\mathrm{N}=137)^{12}$

\begin{tabular}{|c|c|c|}
\hline Profissáo/Ocupaçáo & Ocorrências & \% \\
\hline Faculdade de Direito de São Paulo & 23 & 16,6 \\
\hline Faculdade de Direito de Porto Alegre & 16 & 11,5 \\
\hline Faculdade de Direito do Recife & 14 & 10,1 \\
\hline Faculdade de Direito do Rio de Janeiro & 09 & 6,5 \\
\hline Escola Militar da Praia Vermelha & 7 & 5 \\
\hline Escola Militar da Província do RS & 7 & 5 \\
\hline Escola Politécnica do Rio de Janeiro & 7 & 5 \\
\hline Faculdade de Medicina do Rio de Janeiro & 7 & 5 \\
\hline Outros & 28 & 20,4 \\
\hline Sem informação & 19 & 13,7 \\
\hline
\end{tabular}

Fonte: Banco de Dados Elites Administrativas do RS (1889-1937) / Laboratório de História Comparada do Cone Sul.

Há um predomínio dos nascidos no Rio Grande do Sul (80,7\% ou 105 indivíduos), com forte participação do interior do Rio Grande do Sul (especialmente da metade Sul e regiāo de fronteira), a capital do Estado contando com apenas 17,1\% do total de nascidos no Estado. Apenas em um caso foi identificado como pertencente à região norte do RS (caso de Nicolau Vergueiro, de Passo Fundo). Entre os nascidos fora do Rio Grande do Sul, o Nordeste do país contribui com o maior contingente de indivíduos: 11 casos ou 8,46\% do total. Percebe-se uma significativa presença de bacharéis em Direito oriundos daquela regiáo do país, atraídos para ocupação de cargos no Judiciário estadual (10 casos), como o caso de Manoel André da Rocha (presidente do Tribunal de Apelação do RS entre 1921 e 1935), natural de Natal (RN) e formado pela Faculdade de Direito de Recife (1883), migrou para o Rio Grande do Sul em 1885, fixando-se em definitivo como juiz de direito em Lagoa Ver-

\footnotetext{
${ }^{11}$ Há casos em que as fontes analisadas apontam mais de uma ocupação para os pais.

${ }^{12}$ Há casos de uma dupla formaçáo, como Francisco Rodolfo Simch, formado pela Escola de Minas de Ouro Preto e pela Faculdade de Direito de Porto Alegre.
} 
melha (RS) em junho de 1890 . Outros três $(2,3 \%)$ eram naturais do Rio de Janeiro e para onze indivíduos $(8,4 \%)$ não foi possível descobrir o local de nascimento.

O número elevado de advogados reflete o bacharelismo presente na sociedade da época, combinado com certa especialização (Poder Judiciário), que exige o diploma para ocupação desses cargos. Por sua vez, chama a atenção o alto número de militares (28), mas é explicável pela concentraçáo de militares sul-rio-grandenses na pasta da Guerra (nove nomes), comando da Brigada Militar (sete nomes) e Ministério da Marinha (três nomes), o que reduz para apenas nove os militares em outras pastas, atenuando seu impacto. No caso dos engenheiros, nos 17 casos identificados há quatro engenheiros militares.

Há uma proporção significativa de membros da elite que combinam suas carreiras públicas com a docência. Ser professor é, nessas condiçóes, e possivelmente, mais um marcador de prestígio social que necessariamente uma alternativa econômica. Assim, quase um quinto dos membros da elite (26 casos ou 19,23\%) possuíam vínculos docentes, 13 dos quais na Faculdade de Direito de Porto Alegre (10\% da população total pesquisada), sendo quatro deles seus fundadores; oito (6,15\%) eram professores da Escola de Engenharia de Porto Alegre, tradicional centro de agregação de militantes positivistas nos últimos anos do século XIX e duas primeiras décadas do XX, sendo três fundadores; três foram professores da Faculdade de Medicina de Porto Alegre, sendo um também seu fundador; dois outros atuaram em outras faculdades.

\section{Cargos eletivos}

Embora não seja considerada uma posição/posto de elite na pesquisa de Joseph Love, John Wirth e Robert Levine (exceção feita à presidência das casas legislativas, à liderança da maioria/minoria e à participaçáo nos comitês diretivos dos partidos), o cargo de deputado estadual significou, ainda que considerada a suposta redução da importância do trabalho parlamentar durante o período, para 34,62\% dos agentes ( 45 casos) uma etapa para ascensão em sua carreira política. Obviamente, há um predomínio do partido político ligado ao detentor do poder político do período, como o PRR até a Revolução de 1930. A partir de 1932, tem-se a adesão ao PRL (16 casos), funcionando como base do governo de Flores da Cunha. ${ }^{13}$

O percentual daqueles de nossa elite administrativa que, em algum momento, chegaram à deputação federal é similar. Eles foram 44 ou 33,85\% do total. Não obstante, chega-se mais tarde à Câmara Federal, 38,3 anos é a média de idade do deputado federal em primeiro mandato contra 33 dos deputados estaduais, e se permanece mais tempo. ${ }^{14}$ Em média são

\footnotetext{
${ }^{13}$ Foram identificados 97 agentes ligados a partidos políticos, com 131 ocorrências, podendo aqui incluírem-se mudanças de partido: PRR (80), PRL (16), PF/PL (11), Partido Liberal (Império) (7), Partido Conservador (Império) (3); demais partidos (14).

${ }^{14} \mathrm{O}$ mais jovem deputado estadual, com 24 anos, Firmino Paim Filho, na legislatura de 1909-1913. Entre os deputados federais, o mais jovem foi James Darcy, com 26 anos, em 1903-1905.
} 
3,1 mandatos de deputado federal exercidos contra 2,2 de deputado estadual. Esses números podem sugerir maior importância acordada às carreiras federais entre os políticos regionais, ou quiçá uma conversão mais rápida do cargo estadual em algum posto elevado da administração estadual.

Vale ainda observar o estudo de Wanderley dos Santos (2013) sobre o sistema oligárquico e sua representação na Câmara dos Deputados na Primeira República. Segundo o autor,

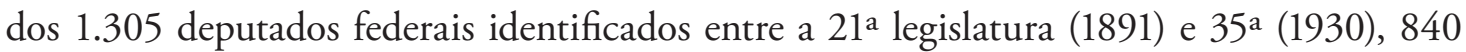
(57\%) não permaneceram mais do que dois mandatos. Ainda assim, trata-se de uma baixa taxa de renovação se comparada ao período do Império, no qual 94\% dos parlamentares não passaram de dois mandatos. Tal lógica apontava para uma estabilidade "governamental e legislativa" (SANTOS, 2013, p. 34) do sistema oligárquico da Primeira República, no qual a taxa de renovação $(0,42)$ era menor se comparado ao regime imperial $(0,65)$. Ou seja, 465 (43\%) mantinham mandatos mais longos e asseguravam os interesses das oligarquias regionais (quando possível) no debate parlamentar.

É possível perceber que, no caso sul-rio-grandense, os valores foram similares, o que demonstra a importância que a elite regional confere para estabilizar o sistema político e estabelecer um meio de trocas políticas com outras elites regionais e com o governo federal, ainda que estabeleça um certo nível de revezamento parlamentar: dos 90 parlamentares sul-rio-grandenses atuantes, $53(58,8 \%)$ não tiveram mais de dois mandatos. É uma tendência que se repetiu com aqueles que integraram a elite administrativa sul-rio-grandense: dos 44 que passaram por cargos de deputados federais, 38 o foram durante a Primeira República, sendo que 23 deles (58\%) alcançaram entre um e dois mandatos. ${ }^{15}$ Para os membros da elite administrativa que permanecem mais do que dois mandatos (42\%), a atuação parlamentar prolongada sugere não só o papel de garantidores da estabilidade do sistema político, por representarem demandas da oligarquia sul-rio-grandense, mas a construção de uma habilitação/especialização para futuras funções ministeriais. ${ }^{16}$

Outro aspecto importante é considerar o perfil similar dos políticos bem-sucedidos em carreiras legislativas estaduais e federais no pós-1930. Ainda que as transformaçóes nos processos eleitorais, a partir da criaçáo de uma Justiça Eleitoral e a incorporação das representaçóes classistas na Assembleia Legislativa e Câmara Federal, é possível observar que os integrantes da elite ainda se destacavam sobre os novos parlamentares sul-rio-grandenses. ${ }^{17}$ No caso da

\footnotetext{
${ }^{15}$ A diferença entre os 22 parlamentares da elite administrativa dos demais 30 que foram meros parlamentares estava no sucesso de suas trajetórias - Getúlio Vargas, João Neves da Fontoura e Osvaldo Aranha integram o primeiro grupo.

${ }^{16}$ Seriam os casos de Ildefonso Simóes Lopes, que se destacaria na Comissão de Agricultura e Viação e Obras Públicas, posteriormente sendo guindado para o Ministério da Agricultura em 1919 ou Carlos Maximilano, atuante na Comissão de Justiça e, posteriormente, Procurador-Geral da República (1934) e Ministro do Supremo Tribunal Federal (1936-1941).

${ }^{17}$ Isso pode ser interpretado como um efeito sobre o que Claudia Viscardi (2001) apontou sobre a Revoluçáo de 1930 não ser aspirado uma ruptura do pacto oligárquico, mas uma tentativa de resgatá-lo.
} 
Câmara Federal, no período da Constituinte de 1934 e a legislatura seguinte (1935-1937), dos 30 indivíduos que atuaram como deputados federais pelo estado, 13 eram integrantes da elite, com alto protagonismo político: por exemplo, Carlos Maximiliano presidiu a Comissão Constitucional da Assembleia (responsável pela elaboração do anteprojeto constitucional federal), Borges de Medeiros foi o candidato "opositor" a Getúlio Vargas na eleição indireta para presidência (recebendo 59 votos) e Joáo Noves da Fontoura desempenhou o papel de líder da minoria no parlamento em sua primeira legislatura até o golpe de $1937 .{ }^{18}$ Ainda que novos políticos ascendessem através das representaçôes classistas (por exemplo, Carlos Santos na Assembleia Legislativa do Rio Grande do Sul, primeiro parlamentar negro), para o período estudado náo eram mais do que coadjuvantes da elite já estabelecida.

De qualquer forma, esse estudo fino da carreira parlamentar e das etapas da conversáo do capital político numa carreira exitosa na administração pública não foi objeto desta pesquisa, sendo necessário investigar mais a fundo esse "salto" entre parlamento e administração antes de avançarmos em outras conclusōes.

Ainda, importa notar que a distribuição das atividades profissionais nos dois níveis de representação é bastante semelhante, com 45,5\% de advogados entre os deputados estaduais contra 59\% entre deputados federais; $20,4 \%$ de engenheiros entre os deputados estaduais contra $18,1 \%$ dos federais; $18,1 \%$ de médicos entre estaduais e $9 \%$ entre federais, um mesmo percentual de militares $(6,8 \%)$ e outras profissôes foram, respectivamente, 9,0 e 6,8 dos casos.

Quadro 2 - Cargos políticos ocupados por membros da elite até o Estado Novo

\begin{tabular}{|c|c|c|}
\hline Cargo & Quantidade & Destaques \\
\hline Prefeito (intendente) & $\begin{array}{c}24 \text { (9 só em Porto } \\
\text { Alegre) }\end{array}$ & $\begin{array}{c}\text { José Montaury (10.074 dias no cargo de prefeito } \\
\text { de Porto Alegre }-1897 \text { a 1924) }\end{array}$ \\
\hline Deputado estadual & 45 & $\begin{array}{c}\text { Manoel Theóphilo Barreto Vianna (10 mandatos) } \\
\text { (1891 a 1928) }\end{array}$ \\
\hline Deputado federal & 44 & $\begin{array}{c}\text { João Simplício Alves de Carvalho, Alexandre } \\
\text { Cassiano do Nascimento, Ildefonso Simóes Lopes } \\
\text { (8 mandatos) }\end{array}$ \\
\hline Senador & 12 & Pinheiro Machado (4 mandatos) (1890 a 1915) \\
\hline Governador19 & 12 & $\begin{array}{c}\text { Antônio Borges de Medeiros (9.129 dias no cargo) } \\
\text { (1898 a 1908; 1913 a1928) }\end{array}$ \\
\hline
\end{tabular}

Fonte: Banco de Dados Elites Administrativas do RS (1889-1937) / Laboratório de História Comparada do Cone Sul.

${ }^{18}$ Deve-se ainda destacar outros membros da elite: Osvaldo Aranha como líder do governo na Assembleia Constituinte (até início de 1934), na qualidade de ministro da Fazenda, e Flores da Cunha, na qualidade de interventor do Rio Grande do Sul, exerceu grande influência nos trabalhos constituintes, a fim de garantir a elegibilidade dos interventores para os governos estaduais.

${ }^{19}$ Não inclui os cargos de interventor federal e membro de Junta Governativa. 
Os números podem indicar as dificuldades de membros da elite em romper certo "isolamento" associado ao posto ocupado, como no caso da Chefia de Polícia. Dos 24 membros, 23 ingressaram na elite assumindo o posto de chefe de Polícia. Porém, apenas sete deles seguiram sua trajetória em outros postos de elite, como Augusto Borges de Medeiros e Manoel André da Rocha.

Há postos que se mostraram inadequados para uma eventual ascensão na hierarquia de posiçôes no Estado. Assim, dos oito intendentes (prefeitos) de Porto Alegre no período analisado, apenas um passou para outra função, e não tão notável: Honorário Felisberto, intendente entre 1896 e 1897, se tornou chefe de Polícia (1897-1904). Igualmente chegar a presidente do Tribunal de Justiça (ou Apelação) pode significar o ponto máximo em uma carreira jurídica para magistrados do RS: dos 11 presidentes, apenas um tornou-se ministro do STF (Antônio de Sousa Martins, em 1894). Não obstante, outros postos "facilitam" acesso a posiçóes privilegiadas na hierarquia funcional da elite regional, como a titularidade das secretarias de Estado (Fazenda, Interior e Obras Públicas), a liderança da maioria na Assembleia Legislativa, o Ministério do Interior e da Justiça e a presidência do Banco do Brasil.

Tabela 5 - Posição de elite e profissão (casos escolhidos)

\begin{tabular}{|c|c|c|c|c|c|}
\hline Posto & Advocacia & Militar & Engenharia & Medicina & Outros \\
\hline $\begin{array}{c}\text { Presidente do Tribunal } \\
\text { de Apelação/Justiça }\end{array}$ & $11(100 \%)$ & - & - & - & - \\
\hline $\begin{array}{c}\text { Comando Brigada } \\
\text { Militar }\end{array}$ & - & $7(100 \%)$ & - & - & - \\
\hline Ministério da Guerra & - & $9(100 \%)$ & - & - & - \\
\hline $\begin{array}{c}\text { Secretária Obras } \\
\text { Públicas }\end{array}$ & $2(16,67 \%)$ & - & $9(75 \%)$ & $1(8,33 \%)$ & - \\
\hline Secretária da Fazenda & $8(50 \%)$ & - & $5(31,25 \%)$ & $2(12,5 \%)$ & $1(6,25 \%)$ \\
\hline Secretária do Interior & $6(54,55 \%)$ & - & $2(18,18 \%)$ & $3(27,27 \%)$ & - \\
\hline Presidência ALRS & - & $2(18,18 \%)$ & $1(9,09 \%)$ & $7(63,64 \%)$ & $1(9,09 \%)$ \\
\hline Intendente POA & - & $2(22,22 \%)$ & $3(33,33 \%)$ & & $4(44,45 \%)$ \\
\hline
\end{tabular}

Fonte: Banco de Dados Elites Administrativas do RS (1889-1937) / Laboratório de História Comparada do Cone Sul

Alguns postos de elite apresentam uma forte identificação com a formação/profissão, como os ligados à carreira jurídica, militar ou de engenharia. Outros, eminentemente políticos (Presidência da ALRS), não apresentam uma tendência (embora o bacharelismo possa predominar). No caso da Presidência da ALRS, contudo, foi constatada a predominância de médicos na funçấo e a ausência completa de advogados (interessante notar que o mais longevo mandato presidencial na casa legislativa do RS coube a um engenheiro). 


\section{Comparativo intergeracional}

Seguindo o critério de Love e Barickman (2006), propomos a divisão da elite em geraçóes, divididas em três grupos: os que nasceram antes de 1869 (e que chegaram à maioridade às vésperas do final do Império), os nascidos entre 1869 e 1888 (e que chegaram à maioridade durante a República Velha e puderam acompanhar a primeira campanha de efetiva competição eleitoral, em 1910), e os nascidos a partir de 1889 (nascidos durante a República e que chegam à maturidade na conjuntura da Revoluçáo de 30). Dos 130 nomes, em cinco casos não foi possível se obter informaçóes sobre data de nascimento. ${ }^{20}$

Tabela 6 - Local de nascimento e profissão por geração

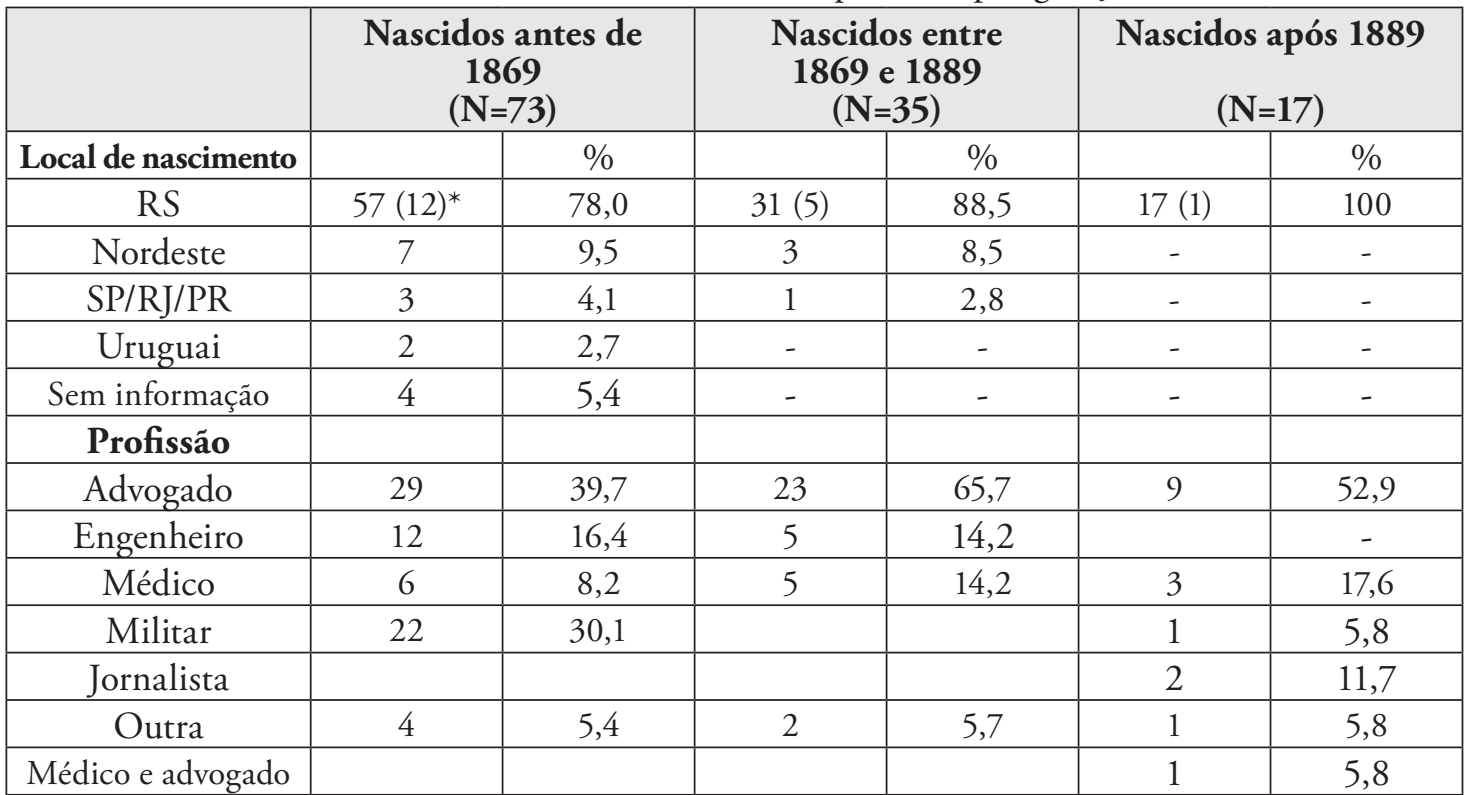

Fonte: Banco de Dados Elites Administrativas do RS (1889-1937) / Laboratório de História Comparada do Cone Sul

* Nascidos na capital

\footnotetext{
${ }^{20}$ Embora em posiçōes de elite, os cinco casos referem-se a incidências únicas: dois chefes de Polícia, um presidente do TJRS, um prefeito de Porto Alegre e um presidente do Banco do Estado do RS. Todos ficaram menos de um ano em seus cargos.
} 
Elites estatais no Sul do Brasil: prosopografia da alta administraÇão republicana no Rio Grande do SUL, I 889-I 937

Flavio Madureira Heinz e Marcelo Vianna

Tabela 7 - Atuação dos membros da elite segundo nível; Idade do $1^{\circ}$ posto; e Ingresso na elite antes dos 40 anos - por geração

\begin{tabular}{|c|c|c|c|c|}
\hline & $\begin{array}{l}\text { Nascidos antes de } \\
1869(\mathrm{~N}=73)\end{array}$ & $\begin{array}{c}\text { Nascidos entre } \\
1869 \text { e } 1889 \\
(\mathrm{~N}=35)\end{array}$ & $\begin{array}{l}\text { Nascidos após } \\
1889(\mathrm{~N}=17)\end{array}$ & Total \\
\hline$\%$ da elite & 56,1 & 26,9 & 13,08 & - \\
\hline $\begin{array}{l}\text { Idade no } 1^{\circ} \text { posto de } \\
\text { elite (média em anos) }\end{array}$ & 49 & 47 & 38 & - \\
\hline $\begin{array}{c}\text { Ingresso na elite antes } \\
\text { do } 40 \text { anos }(\%)\end{array}$ & 28,7 & 28,5 & 58 & - \\
\hline $\begin{array}{c}\text { Apenas atuação } \\
\text { estadual }\end{array}$ & $46(72)^{* *}$ & $24(35)^{*}$ & $13(19)^{*}$ & $83(126)$ \\
\hline $\begin{array}{l}\text { Apenas atuação } \\
\text { federal }\end{array}$ & $16(26)$ & $8(13)$ & $01(02)$ & $25(41)$ \\
\hline $\begin{array}{l}\text { Atuação estadual/ } \\
\text { federal }\end{array}$ & $11(27)$ & 03(08) & 03(11) & $17(46)$ \\
\hline $\begin{array}{l}\text { Total de postos } \\
\text { assumidos }\end{array}$ & (125) & (56) & (32) & (213) \\
\hline
\end{tabular}

Fonte: Banco de Dados Elites Administrativas do RS (1889-1937) / Laboratório de História Comparada do Cone Sul.

* Para 5 casos não foi possível determinar a data de nascimento

**Entre parênteses o número de postos ocupados no respectivo nível de atuação.

Entre os nascidos antes de $\mathbf{1 8 6 9}$ encontram-se os próceres do PRR, liderados por Júlio de Castilhos e Borges de Medeiros: Pinheiro Machado, Carlos Barbosa, Manoel Theóphilo Barreto Vianna, José Parobé. Também estão presentes os dissidentes e rivais, como Fernando Abbott, Assis Brasil, Antão de Faria e Gaspar Silveira Martins. Entre as características desses indivíduos, estava a presença mais duradoura em postos de elite, o que pode ser explicado, em alguns casos, pela militância no republicanismo histórico antes do advento da República e na sua capitalizaçáo como recurso na disputa por altos postos na estrutura do Estado. Naturalmente, ao ocuparem os cargos após a consolidação do poder do PRR tenderam a controlar um maior número de postos.

Entre os membros da geração dos nascidos entre 1869 e 1888, encontram-se quatro integrantes da Geração de 1907 (LOVE, 1975; GRIJÓ, 1998; 2017). O termo "geração de 1907” foi originalmente concebido por Joseph Love para designar um grupo de lideranças políticas que iniciaram seu percurso a partir do governo de Borges de Medeiros. Essas lideranças - José Flores da Cunha, Firmino Paim Filho, Lindolfo Collor, Getúlio Vargas, Osvaldo Aranha, Maurício Cardoso e Joáo Neves da Fontoura - detinham uma série de características comuns (faixa etária, herança política, atuação no PRR, formação acadêmica superior, experiência em conflitos) e alcançaram proeminência no campo político regional e nacional. Joseph Love observou que quatro deles (Vargas, Joáo Neves, Paim Filho e Cardo- 
so) iniciaram sua carreira política em 1907, participando do Bloco Acadêmico Castilhista e atuando incisivamente na eleição de Carlos Barbosa para o governo estadual (1908-1912). O trabalho de Luiz Alberto Grijó aprofundou o entendimento sobre essa "Geração", dissecando suas trajetórias até 1930 a fim de estabelecer como os recursos e em que condiçóes esses "agentes engajados em uma concorrida disputa pela conquista de posiçóes dominantes no jogo político" estabeleceram sua ascensão.

Para Luiz A. Grijó (1998) os membros da "Geração de 1907" detinham a capacidade de mediação requerida entre os coronéis (herança política, domínio de uma clientela de correligionários e peóes) para estabelecer seu domínio local. Mas o que os destacava perante os demais era a capacidade de se afastarem das origens rurais, extrapolando a dinâmica paroquial ao incorporarem recursos jurídicos e culturais (atuação como advogados e jornalistas), e estabelecerem uma rede de contatos com políticos e militares de outros Estados. Enfim, o que determinou o sucesso da "Geração" foi sua capacidade de reconversão de recursos e de trânsito entre as diferentes esferas (da paróquia, estadual e nacional) como prova do domínio das lógicas inerentes a cada esfera. Isso não só determinou sucesso em obterem cargos de destaque ao longo de suas trajetórias, mas também em construírem uma notabilidade por seus feitos e por posições alcançadas. Como exemplo, Grijó (1998, p. 236) observou na biografia de Osvaldo Aranha (O’DONNELL, 1980), a presença de várias "qualidades" desse político, tais como ser um "jurista", "benfeitor", "advogado do Brasil", "diplomata" e "revolucionário".

Assim, os membros da "Geração" puderam concentrar posiçôes de destaque político a partir do início dos anos 1920. Isso se deu pela capacidade de mediação da "Geração" em relação a Borges de Medeiros - colocada à prova em vários momentos, como a disputa interpartidária do PRR (que alijou temporariamente a família Vargas do poder, em São Borja, e família Neves da Fontoura, em Cachoeira do Sul), e a prova de fidelidade ao partido na Revolução de 1923, que exigiu que eles recrutassem suas clientelas, pegassem em armas ou defendessem o governo na tribuna estadual/federal. Suas açôes nesse último conflito permitiram obter reconhecimento, exercitar a aproximaçáo com a oposiçáo do PRR e organizar a ocupação política do Estado afastando-se do velho "patriarcado" do partido. Isso também os tornou capazes de exercer mediação na esfera nacional, a ponto de tornarem-se protagonistas da Aliança Liberal e da própria Revolução de 1930. 
Quadro 3 - Características dos membros da Geração de 1907

\begin{tabular}{|c|c|c|c|}
\hline Membro "Geração" & $\begin{array}{c}\text { Contribuiçãao } \\
\text { Revolução } \\
1923 \\
\end{array}$ & $\begin{array}{c}\text { Primeiros cargos da } \\
\text { trajetória }\end{array}$ & $\begin{array}{l}1^{\text {a }} \text { posição de } \\
\text { destaque }\end{array}$ \\
\hline $\begin{array}{l}\text { João Neves da } \\
\text { Fontoura }\end{array}$ & Armas & $\begin{array}{c}\text { Intendente Cachoeira do Sul } \\
\text { (1912) } \\
\text { Deputado estadual (1921) } \\
\end{array}$ & $\begin{array}{c}\text { Líder maioria } \\
\text { Assembleia (1923) }\end{array}$ \\
\hline Osvaldo Aranha & Armas, ferido & $\begin{array}{c}\text { Intendente Alegrete (1925) } \\
\text { Deputado estadual (1926) } \\
\text { Deputado federal (1927) }\end{array}$ & $\begin{array}{l}\text { Secretário de Interior } \\
\text { (1928) }\end{array}$ \\
\hline $\begin{array}{l}\text { José Antônio Flores da } \\
\text { Cunha }\end{array}$ & Armas & $\begin{array}{c}\text { Deputado estadual (1909) } \\
\text { Deputado federal (1912) } \\
\text { Intendente Uruguaiana (1917) } \\
\text { Deputado federal (1923) } \\
\text { Senador (1928) } \\
\end{array}$ & $\begin{array}{c}\text { Interventor Federal } \\
\text { do Rio Grande do Sul } \\
\text { (1930) }\end{array}$ \\
\hline Getúlio Vargas & Tribuna & $\begin{array}{c}\text { Deputado estadual (1909) } \\
\text { Deputado federal (1923) }\end{array}$ & $\begin{array}{c}\text { Ministro da Fazenda } \\
(1926)\end{array}$ \\
\hline Lindolfo Collor & Tribuna & $\begin{array}{l}\text { Deputado estadual (1921) } \\
\text { Deputado federal (1926) }\end{array}$ & $\begin{array}{c}\text { Ministro do Trabalho } \\
(1930)\end{array}$ \\
\hline Firmino Paim Filho & Armas & $\begin{array}{c}\text { Intendente Vacaria (1908) } \\
\text { Deputado estadual (1909) } \\
\text { Deputado federal (1924) }\end{array}$ & $\begin{array}{l}\text { Secretário da Fazenda } \\
\text { (1929) }\end{array}$ \\
\hline $\begin{array}{l}\text { Joaquim Maurício } \\
\text { Cardoso }\end{array}$ & Tribuna & Deputado estadual (1913) & $\begin{array}{c}\text { Ministro da Justiça } \\
\text { (1931) }\end{array}$ \\
\hline
\end{tabular}

Fonte: Banco de Dados Elites Administrativas do RS (1889-1937) / Laboratório de História Comparada do Cone Sul.

A partir da Revoluçáo de 1930, caracterizou-se um rompimento entre alguns membros da "Geração", como Neves da Fontoura, o que indicava conflito entre posiçóes a serem obtidas e o poder de quem determinava sua concessão (Getúlio Vargas). Em relação aos nascidos a partir de 1889, o baixo número (17) de indivíduos sugere a dificuldade em encontrar espaço na estrutura estatal frente aos demais agentes. Ainda assim, temos três membros da Geração de 1907 (LOVE, 1975; GRIJÓ, 1998) - Osvaldo Aranha, Lindolfo Collor e João Neves da Fontoura - que parecem ter obtido maior sucesso em ocupar postos de elite. 
Elites estatais no Sul do Brasil: prosopografia da alta administraÇão Republicana no Rio Grande do SUL, I 889-I 937

Flavio Madureira Heinz e Marcelo Vianna

Tabela 8 - Comparação gerações RS e gerações de elites brasileiras (SP, MG, PE) descritas por Love e Barickman (2006, p. 88)

\begin{tabular}{|c|c|c|c|c|c|c|}
\hline Membros & $\begin{array}{c}\text { Experiência } \\
\text { legislativa } \\
\text { (LOVE; } \\
\text { BARICKMAN) }\end{array}$ & $\begin{array}{c}\text { Experiência } \\
\text { legislativa } \\
\text { (RS) }\end{array}$ & $\begin{array}{c}\text { Ingresso elite } \\
\text { antes dos 40 } \\
\text { anos (LOVE; } \\
\text { BARICKMAN) }\end{array}$ & $\begin{array}{c}\text { Ingresso } \\
\text { elite antes } \\
\text { dos } 40 \text { anos } \\
\text { (RS) }\end{array}$ & $\begin{array}{c}\text { Profissáo } \\
\text { Engenheiro } \\
\text { (LOVE; } \\
\text { BARICKMAN }\end{array}$ & $\begin{array}{c}\text { Profissão } \\
\text { Engenheiro } \\
\text { (RS) }\end{array}$ \\
\hline $\begin{array}{c}\text { Nascidos } \\
\text { antes de } \\
1869\end{array}$ & $71,7 \%$ & $53,42 \%$ & $25,6 \%$ & $28,77 \%$ & $7,1 \%$ & $16,43 \%$ \\
\hline $\begin{array}{c}\text { Nascidos } \\
\text { entre } \\
1869-1888\end{array}$ & $60 \%$ & $51,43 \%$ & $29,3 \%$ & $28,57 \%$ & $12,5 \%$ & $14,29 \%$ \\
\hline $\begin{array}{c}\text { Nascidos a } \\
\text { partir de } \\
1889\end{array}$ & $52,6 \%$ & $58,82 \%$ & $69 \%$ & $58 \%$ & $5,5 \%$ & $0 \%$ \\
\hline
\end{tabular}

Fonte: Banco de Dados Elites Administrativas do RS (1889-1937) / Laboratório de História Comparada do Cone Sul

Não há uma grande divergência entre os dados que são passíveis, no momento, de comparação - a experiência legislativa se mantém estável no caso sul-rio-grandense, com leve crescimento para a última geração. A idade de ingresso na elite é também muito próxima. No caso dos engenheiros, sua presença relativamente importante na primeira geração poderia sugerir o impacto do Positivismo e da tese da conformação de uma "administração científica" no RS, materializada na ocupação de cargos "técnicos" (como a Secretaria de Obras Públicas), mas, a longo prazo, percebe-se um fechamento na ocupação de posições de elite a engenheiros na terceira geração.

\section{Conclusões}

Uma das principais evidências oferecidas pela análise dos dados diz respeito à dimensão das populaçôes pesquisadas. Assim, enquanto as populaçôes estudadas por Love, Wirth e Levine perfaziam 263 indivíduos em São Paulo, 214 em Minas Gerais, e 276 em Pernambuco, ao longo dos 48 anos do período em análise, uma estrutura análoga de posiçóes foi ocupada por apenas 130 indivíduos no caso do Rio Grande do Sul. As características dessa elite passam por um grau apreciável de fechamento, evidenciado pela baixa rotatividade na ocupação dos cargos e longas carreiras públicas. Essa baixa rotatividade se percebe na análise das posiçōes estaduais, não apenas no cargo máximo do Executivo, mas também nas secretarias. No espaço de 48 anos, a Secretaria de Obras Públicas viu passar em sua chefia 12 nomes, sendo que João José Pereira Parobé permaneceu no cargo 18,2 anos, enquanto

\footnotetext{
${ }^{21}$ Não está contabilizado um deputado estadual (não foi identificado data de nascimento para incluí-lo em uma geração).
} 
Ildefonso Soares Pinto atuou 8,5 anos. Tal feito pode ser percebido também em outros poderes, como o posto de presidente do Tribunal de Apelação - de 12 nomes, destacam-se James de Oliveira Franco e Souza, 19,7 anos, e Manoel André da Rocha, 14,18 anos.

Há exceçôes, notoriamente o cargo de chefe de Polícia - entre 1891 e 1937, ocorreram 30 nomeaçôes de titulares, perfazendo um tempo médio de 1,5 anos no posto (contados interinos, a média é inferior a um ano). Embora de relevância, o cargo pode ser definido como transicional para obtenção de prestígio político e jurídico, uma posição-chave do cursus honorum da grande política regional, sobretudo pela visibilidade social (imprensa) que oferecia na manutenção da ordem através da repressão da criminalidade, de adversários políticos e dos movimentos sociais. Náo por acaso, Borges de Medeiros (1895-1897) e Manoel André da Rocha (1904-1905), ocuparam o posto, alcançando, respectivamente, o cargo de presidente do Estado e presidente do Tribunal de Apelação do RS.

Ainda, percebe-se reduzida presença da elite regional do Rio Grande do Sul em altos cargos de nível federal no período, sobretudo se confrontados às elites paulistas e mineiras. No Ministério da Fazenda, por exemplo, entre 1891 e 1930, cinco gaúchos ocuparam a pasta (incluindo interinos), perfazendo a média de um ano de carreira - apenas Homero Batista teve um mandato apreciável, 3,4 anos, entre 1919 e 1922. Esse quadro muda a partir da ascensão de Vargas ao poder, quando Osvaldo Aranha e Artur de Souza Costa assumem, respectivamente, em 1931 e 1934. Também, o quadro é outro no que se refere às carreiras militares: serão oito ministros da Guerra oriundos do RS no período.

Outro ponto de interesse diz respeito às possíveis relaçôes existentes entre a prevalência da orientação ideológica (positivista) da elite política republicana do Sul do país e o recrutamento da alta administração pública. Assim, parte da literatura pertinente sugeriu que uma administração de corte mais "científico", orientada por preceitos positivistas e fundada no recrutamento de engenheiros, tenha caracterizado a experiência da Primeira República no Rio Grande do Sul, uma particularidade regional em um país de resto marcado pela onipresença dos bacharéis em Direito na vida pública (DIAS, 1994). Ora, a análise dos dados coletados não conforta essa ideia. Com efeito, o número de engenheiros nas posiçóes centrais é reduzido, apenas 16 em 130 indivíduos analisados ou 12,3\% do total.

Por outro lado, o padrão brasileiro de formação da elite política e alta administração pública nas faculdades de Direito se confirma aqui, mas de forma atenuada: eles são 66, ou $50 \%$ do total - contra $70 \%$ no somatório dos outros três estados mencionados -, a possuir formaçáo de advogado (LOVE; BARICKMAN, 2006, p. 79). No caso da origem "militar" do membro da elite político-administrativa regional, a diferença em relação ao padrão nacional é enorme: no RS, são 27 indivíduos (dos quais cinco engenheiros-militares e sete militares de carreira estadual, na Brigada Militar do RS), pouco mais de $20 \%$ do total, contra 3\% no somatório das elites regionais de SP, MG e PE (LOVE; BARICKMAN, 2006, p. 82). 
Por fim, ainda que não seja o escopo desta pesquisa, vale destacar a necessidade de se explorar futuras comparaçóes com outras elites regionais entre os anos de 1891 e 1937. Os desafios encontram-se na ausência de dados prosopográficos sistematizados dessas realidades, que impedem de definir seus tamanhos a priori. Em alguns casos, como Ceará, Mato Grosso (ARRUDA, 2015) e mesmo Bahia (PANG, 1979), suas dinâmicas políticas revelam uma dificuldade das elites regionais em estabilizar seus sistemas políticos e administrativos, dadas disputas entre os grupos oligárquicos pelo poder. ${ }^{22}$ Isso pode gerar elites com menos poder, sujeitos a interferências do governo federal ou de elites regionais politicamente mais articuladas.

O número circunscrito de membros da elite administrativa sul-rio-grandense revela que este pequeno grupo assim está constituído por motivos distintos. Não se tratou de uma "administração científica" do Estado, mas de um grupo político forjado no autoritarismo ter a capacidade de se firmar no poder ainda no início da Primeira República. Enquanto a Bahia, por exemplo, experimentou períodos de revezamento nos espaços de poder, levando a momentos de formação de "estados dentro do estado", com ampla autonomia dos coronéis (PANG, 1979), no Rio Grande do Sul a oposição política fora dizimada pela Revolução de 1893 e o grupo no poder pôde exercer controle absoluto do aparato judicial/policial e estabelecer uma relação de autoridade sobre os coronéis. Apesar de haver dissensos, o Pacto de Pedras Altas ${ }^{23}$, em 1923, aproximaria a oposição e o governo, mantendo o caráter fechado da elite sul-rio-grandense. Em seguida, a Revoluçáo de 1930 guindaria parte dessa elite para altos postos políticos e administrativos do governo federal.

Dessa forma, e mesmo levando-se em conta a centralidade de fontes "regionais" para a pesquisa aqui relatada, o resultado colabora à diversificaçáo do quadro até hoje conhecido sobre o funcionamento das elites políticas de extração regional atuantes no plano nacional.

\section{Referências}

ABREU, Alzira A. de (coord.). Dicionário histórico-biográfico da Primeira República. Rio de Janeiro: FGV, 2015.

\footnotetext{
${ }^{22}$ Um exemplo foi o Estado de Mato Grosso, que experimentou disputas oligárquicas em 1892, 1899, 1906, 1916, sem que houvesse duradoura proeminência política do grupo vencedor (ARRUDA, 2015). Isso levou à alternância de 31 presidências do Estado, entre famílias oligarcas e interventores, com evidentes efeitos nas nomeações de secretariados estaduais.

${ }^{23}$ O Pacto de Pedras Altas, assinado em 14 de dezembro de 1923, selou a paz no conflito intraelite que opôs militarmente, no Rio Grande do Sul, o establishment republicano reunido em torno do governador Borges de Medeiros e uma frente de oposição liberal liderada por José Francisco de Assis Brasil. O Pacto garantiu a permanência - entáo contestada - de Borges à frente do governo até o final do mandato, mas impossibilitou sua reeleição, além de estabelecer normas para a escolha e dos próximos vice-presidentes do Estado e procedimentos eleitorais compatíveis com a legislação federal (ABREU, 2015).
} 
ARRUDA, Larissa R. Vacari de. Disputas oligárquicas: as práticas das elites mato-grossenses (1892-1906). São Carlos: EDUFSCAR/FAPESP, 2015.

AXT, Gunter. Gênese do estado moderno no Rio Grande do Sul, 1889-1929. Porto Alegre: Paiol, 2011.

BOSI, Alfredo. A arqueologia do Estado-providência: sobre um enxerto de ideias de longa duração. In: BOSI, Alfredo. Dialética da colonização. São Paulo: Companhia das Letras, 1992.

DIAS, José Luciano de Mattos. Os engenheiros do Brasil. In: GOMES, Angela Castro. Engenheiros e economistas: novas elites burocráticas. Rio de Janeiro: Ed. FGV, 1994.

GIL, Tiago L. Como se faz um banco de dados (em História). Porto Alegre: Ladeira Livros, 2015.

GRIJÓ, Luiz A. O jogo das mediaçôes: Getúlio Vargas e sua geração no Rio Grande do Sul da $1^{a}$ República. Porto Alegre: Homo Plasticus, 2017.

GRIJÓ, Luiz A. Origens sociais, estratégias de ascensão e recursos dos componentes da chamada "Geração de 1907”. Dissertação (Mestrado em Ciência Política) - Universidade Federal do Rio Grande do Sul, Porto Alegre, 1998.

HEINZ, Flavio M. La création de l'Institut d'électrique de l'École d'ingénieurs de Porto Alegre et la formation des premiers ingénieurs électrotechniciens dans le sud du Brésil (1908). In: EFMERTOVÁ, M.; GRELON, A.; MIKES, J. (eds.) Des ingénieurs pour un monde nouveau - Histoire des enseignements électrotechniques (Europe, Amériques) $-X I X^{e}-X X^{e}$ siècle. Bruxelas: Peter Lang, 2016.

HEINZ, Flavio M. (org). Por outra história das elites. Rio de Janeiro: Editora FGV, 2006 a. HEINZ, Flavio M. Elites, estado y reforma en Uruguay y Brasil meridional: castilhismo y batllismo en perspectiva comparada. El caso de las elites de Rio Grande do Sul en la transición del siglo XIX al XX. In: REGUERA, Andrea (org.). Los rostros de la modernidad: vías de transición al capitalismo. Europa y América Latina, siglos XIX y XX. Rosario: Prohistoria Ed., 2006b. p. 112-135.

HEINZ, Flavio M. Positivistas e republicanos: os professores da Escola de Engenharia de Porto Alegre entre a atividade política e a administração pública (1896-1930). Revista Brasileira de História, Sáo Paulo, v. 29, n. 58, p. 263-289, 2009.

HEINZ, Flavio M. Entrevista com Joseph Love. Estudos Históricos, Rio de Janeiro, n. 32, p. 165-177, 2003.

HEINZ, Flavio M.; CODATO, A. A prosopografia explicada para os cientistas políticos. In: PERISSINOTTO, R.; CODATO, A. Como estudar elites. Curitiba: Editora UFPR, 2015. HERRLEIN JR., Ronaldo. Rio Grande do Sul, 1889-1930: um outro capitalismo no Brasil meridional? Tese (Doutorado em Economia) - Unicamp, Campinas/SP, 2000. 
LEVINE, Robert. A velha usina: Pernambuco na federação brasileira. Rio de Janeiro: Paz e Terra, 1980.

LOVE, Joseph L.; BARICKMAN, Bart. Rulers and Owners - a Brazilian case study in comparative perspective. $H A H R$, v. 66, n. 4, p. 743-765, 1986.

LOVE, Joseph L. Regional elites. In: CONNIFF, M.; McCANN, F. (eds.). Modern Brazil: elites and masses in historical perspective. Lincoln: University of Nebraska Press, 1991. p. $3-22$.

LOVE, Joseph; BARICKMAN, Bart. Elites regionais. In: HEINZ, Flavio M. (org). Por outra história das elites. Rio de Janeiro: Editora FGV, 2006.

LOVE, Joseph. O regionalismo gaúcho e as origens da Revolução de 1930. São Paulo: Perspectiva, 1975.

LOVE, Joseph. A locomotiva. São Paulo na federação brasileira. Rio de Janeiro: Paz e Terra, 1982.

O’DONNELL, F. Talaia. Oswaldo Aranha. Porto Alegre: Sulina, 1980.

PANG, Eul-Soo. Coronelismo e oligarquias (1889-1934): a Bahia na Primeira República brasileira. Rio de Janeiro: Civilização Brasileira, 1979.

SANTOS, Wanderley Guilherme dos. O sistema oligárquico representativo da Primeira República. Dados, v. 56, n. 1, p. 9-37, 2013.

STONE, Lawrence. Prosopografia. Revista de Sociologia Politica, Curitiba, v. 19, n. 39, p. 115-137, jun. 2011.

TARGA, Luiz Roberto Pecoits. Le Rio Grande do Sul et la création de l'État "développementiste" brésilien. Tese (Doutorado em Ciências Econômicas) - Université Pierre Mendes France, Grenoble, 2002.

TRINDADE, Helgio. O jacobinismo castilhista e a ditadura positivista no Rio Grande do Sul. In: TRINDADE, Helgio (org.). O Positivismo: teoria e prática - sesquicentenário da morte de Augusto Comte. Porto Alegre: Ed. UFRGS, 2007. p. 485-497.

VIANNA, Marcelo. Uma base de dados para membros de carreiras técnicas: estudo sobre os promotores públicos do Rio Grande do Sul (1930-1964). História UNICAP, v. 5, n. 10, p. 376-395, 2018.

VISCARDI, Claudia. O teatro das oligarquias: uma revisão da política do café com leite. Belo Horizonte: C/Arte, 2001.

WIRTH, John. O fiel da balança. Minas Gerais na Federação brasileira. Rio de Janeiro: Paz e Terra, 1982. 